\title{
Alpha-2A Adrenergic Receptor Subtype Gene Expression in the Intestines of Cocaine-Exposed Rat Embryos
}

\author{
LAURA P. WARD, JOANNA M. HILL, AND SUSAN K. McCUNE \\ Department of Neonatalogy, Children's National Medical Center, Washington D.C., U.S.A. [L.P.W., \\ S.K.M.]; National Institute of Child Health and Human Development, National Institutes of Health, \\ Bethesda, Maryland, U.S.A. [L.P.W., S.K.M., J.M.H.]
}

\begin{abstract}
ABST
Cocaine has become a popular illicit drug in our society, and
pregnant women are not immune from this epidemic. Recently,
there have been several references in the literature describing an
association between prenatal cocaine exposure and the subse-
quent development of necrotizing enterocolitis in the neonate,
but the mechanism underlying this relationship remains specu-
lative. Because $\alpha$-2 adrenergic receptors are thought to play a
role in the autoregulatory mechanism in the newborn intestine
that responds to hypoxia and ischemia, we examined the expres-
sion of this receptor in the intestine of embryonic rats exposed to
low- and high-dose cocaine in utero. Pregnant Sprague Dawley
rats were injected daily with either saline, low-dose cocaine, or
high-dose cocaine beginning on embryonic d 5 (E 5$)$ and con-
tinuing to E 20. Mothers were killed on E $16, \mathrm{E} 17, \mathrm{E} 18$, E 19 ,
and E 20. Embryos were frozen and stored at $-80^{\circ} \mathrm{C}$. In situ
hybridization was performed on 20 - $\mu \mathrm{m}$ sections with ${ }^{35} \mathrm{~S}-\mathrm{labeled}$
\end{abstract}
\section{ABSTRACT}

oligonucleotide probes specific for the $\alpha$-2A adrenergic receptor subtype. Densitometric analysis revealed a significant decrease in the $\alpha-2 \mathrm{~A}$ receptor expression in the intestine of both the lowdose and high-dose cocaine-exposed animals compared with controls. This down-regulation was demonstrated by E 17, and continued through the remainder of gestation. These changes may limit the normal adaptation to vasoconstriction, thus exacerbating the already insufficient compensatory mechanisms for responding to ischemic injury, and thus may be one of the important factors predisposing cocaine-exposed infants to necrotizing enterocolitis. (Pediatr Res 52: 504-508, 2002)

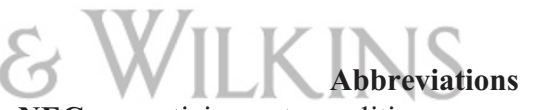

NEC, necrotizing enterocolitis

E, embryonic day
The prevalence of cocaine use in women of child-bearing age has increased significantly in recent years, resulting in considerable morbidity and mortality in neonates exposed to cocaine in utero. It has been estimated that $17 \%$ of pregnant women in an urban setting have used cocaine at some point during pregnancy (1). Cocaine exposure has been associated with many perinatal complications, including placental abruption, prematurity, intrauterine growth retardation, cerebral infarcts, developmental delay, limb reduction defects, and other vascular disruptions $(2,3)$. In the pregnant mother, cocaine causes an $\alpha$-adrenergic-mediated mesenteric and uterine vascular constriction resulting in a dose-dependent decrease in uterine blood flow (4). These uterine blood flow changes can jeopardize the fetus by causing profound hypoxemia, resulting

Received March 1, 2001; accepted March 18, 2002.

Correspondence: Laura P. Ward, Division of Neonatology, Cincinnati Children's Hospital Medical Center, 3333 Burnet Avenue, Cincinnati, Ohio 45229-3039, U.S.A.; e-mail laura.ward@chmcc.org

Supported by a grant from Children's National Medical Center Research Advisory Council.

DOI: 10.1203/01.PDR.0000030883.20888.E6 in decreased fetal oxygenation and hypotension. Furthermore, cocaine can cross the placenta and produce levels in the fetus that are up to $10 \%$ of the mother's (4). This can lead to fetal tachycardia and hypertension-posing further hazard to the fetus.

Recently, there have been several references in the literature linking in utero cocaine exposure and the subsequent development of NEC in the neonate. These include several case reports of either NEC or intestinal infarction following maternal cocaine use $(2,3,5-8)$. In addition, several studies have found an increased risk of NEC in cocaine-exposed newborns compared with nonexposed controls (9-12). One of these studies reported that the cocaine-exposed infants with NEC tended to develop more severe disease, were more likely to require surgery, and had a higher mortality rate (13). To date, there is only one animal study linking prenatal cocaine exposure to the subsequent development of NEC in the newborn. Buyukunal et al. (14) noted a dose-dependent relationship between in utero cocaine exposure and the development of histopathologic changes consistent with NEC in rat pups. This same group reported significant decreases in the perfusion of the uterus, 
placenta, and fetus in cocaine-exposed pregnant rats compared with controls in a more recent study (15). Despite these findings, however, the definitive mechanism underlying the interaction between cocaine exposure and the subsequent development of NEC remains largely speculative.

Cocaine administration is known to cause an increase in the extracellular levels of several neurotransmitters, including norepinephrine, epinephrine, dopamine, and serotonin by blocking their reuptake in the synaptic cleft (16). This then leads to their accumulation at postsynaptic receptor sites, and therefore to activation of adrenergic receptors - the family of G proteincoupled receptors that mediate tissue responses to catecholamines (17). These receptors were originally subdivided into $\alpha$ and $\beta$ types based on pharmacologic differences; however, more extensive studies have allowed further subclassification into $\alpha-1$ and $\alpha-2$ subtypes. Most recently, molecular techniques have led to the cloning of several subtypes of both the $\alpha-1$ and $\alpha-2$ adrenergic receptors (17). At least three distinct human $\alpha-2$ adrenoceptor subtypes have been identified to date: the $\alpha-2 \mathrm{~A}$, the $\alpha-2 \mathrm{~B}$, and the $\alpha-2 \mathrm{C}$ (18). Although linking function to specific receptor subtypes has been difficult due to insufficient subtype-specific ligands (17), there are studies that have associated $\alpha-2$ adrenergic receptors with the regulation of intestinal motility and intestinal water and electrolyte absorption (19-21). There is also data to suggest that $\alpha-2$ adrenergic receptors are present on endothelial cells and can mediate vascular relaxation when activated (22). In addition, there is evidence that the $\alpha-2$ adrenergic receptors may regulate intestinal vasodilation under hypoxic or ischemic conditions (23). Therefore, based on the increased availability of the monoaminergic neurotransmitters after cocaine administration and the role that adrenergic receptors play in maintaining intestinal vasomotor tone, we sought to determine the effect of in utero cocaine exposure on the expression of the $\alpha-2 \mathrm{~A}$ adrenergic receptor in the intestine of the fetal rat.

\section{METHODS In}

Animals. The study was performed with the approval of the Animal Research Committee of the Children's National Medical Center (ARC \# 65/97/04). Timed pregnant Sprague Dawley rats were obtained from Harlan Bioproducts for Science (Indianapolis, IN, U.S.A.) at $3 \mathrm{~d}$ of gestation and were allowed to acclimate for $2 \mathrm{~d}$ before the initiation of the study. The rats were housed under standard conditions and were allowed free access to rat chow and water. Beginning on E 5 and continuing until E 21 (term is generally $21 \mathrm{~d}$ ), the animals received daily s.c. injections of either saline (control group), $30 \mathrm{mg} / \mathrm{kg}$ of cocaine (low-dose group), or $75 \mathrm{mg} / \mathrm{kg}$ of cocaine (high-dose group). Before receiving the injections, the rats were anesthetized with inhalational isoflurane.

Tissue preparation. The pregnant rats were killed by decapitation after receiving inhalation isoflurane for anesthesia. Sacrifice occurred at various points during the pregnancy, beginning on E 16 and continuing until E 20. The fetuses were frozen on 2-methylbutane on dry ice and stored at $-80^{\circ} \mathrm{C}$ until ready for use. Frozen sections of these animals were cut on a cryostat, $20 \mu \mathrm{g}$ thick, and were mounted onto twice subbed gelatin slides and subsequently frozen at $-80^{\circ} \mathrm{C}$. Before in situ hybridization, the slides were thawed at room temperature for $10 \mathrm{~min}$ and were subsequently fixed with $4 \%$ formaldehyde in PBS and then processed as described previously (24). The sections were placed in $0.25 \%$ acetic anhydride in $0.1 \mathrm{M}$ triethanolamine $(\mathrm{pH} 8.0)$ for $10 \mathrm{~min}$. They were then dehydrated sequentially in ethanols, $70 \%$ for $1 \mathrm{~min}, 80 \%$ for $1 \mathrm{~min}$, $95 \%$ for $2 \mathrm{~min}$, and $100 \%$ for $1 \mathrm{~min}$. The sections were placed in chloroform for $5 \mathrm{~min}$ followed by $100 \%$ ethanol for $1 \mathrm{~min}$ and $95 \%$ ethanol for $1 \mathrm{~min}$. The slides were allowed to air dry before use for hybridization.

In-situ hybridization. The sections were hybridized in a solution of $50 \%$ formamide, $1 \mathrm{X}$ Denhardt's solution, and a $10 \%$ dextran sulfate with $500 \mu \mathrm{g} / \mathrm{mL}$ of salmon sperm DNA and $100 \mathrm{mM}$ fresh DTT. Each slide (with two to four sections per slide) was incubated with $130 \mu \mathrm{L}$ of hybridization solution containing 1-3 $\times 10^{6} \mathrm{cpm}$ of ${ }^{35} \mathrm{~S}$-labeled probe overnight at $37^{\circ} \mathrm{C}$. To prevent drying of the slides, they were covered with parafilm coverslips after probe addition. After the overnight hybridization, the parafilm coverslips were floated off in $1 \mathrm{X}$ SSC and the slides were washed in $2 \mathrm{X} \mathrm{SSC}$ with $50 \%$ formamide at $40^{\circ} \mathrm{C}$ for $1 \mathrm{~h}$ with three changes followed by a 1-h wash at room temperature in $1 \mathrm{X}$ SSC with two changes. The slides were dipped quickly in water and then $70 \%$ ethanol and allowed to air dry before placing them against Amersham $\beta$-Max film (Amersham Pharmacia Biotech, Piscataway, NJ, U.S.A.) and exposing them for $11-17 \mathrm{~d}$ at room temperature. Control, low-dose, and high-dose slides were placed on the same film. The film was developed in D19 for 4 min followed by stop bath for $2 \mathrm{~min}$, fix for $4 \mathrm{~min}$, and then washed in water for 20 min before air drying.

Probe preparation. Oligonucleotide probes $42-45$ bp in length were synthesized on a model 380B DNA synthesizer (Applied Biosystems, Foster City, CA, U.S.A.) and were purified on polyacrylamide gels. The probes were derived from rat cDNA sequences for the $\alpha-2 \mathrm{~A}$ adrenergic receptor subtype. These probes have previously been shown to be specific for the $\alpha-2$ A receptor subtype (25). The sequences are as follows:

\section{5' 'CTCACACGATGCGCTTTCTGTCGCCACGGCAG- AGGATCTTCTTGA}

\section{5' GAACGTGAAGCGTTTCTCGCGGTTCTGCCTCC-} CGCGCCACCGGAC

For all of the in situ studies, a 20X excess of unlabeled probe was used as control. The probe was $3^{\prime}$ end-labeled using terminal deoxynucleotidyl transferase (Bethesda Research Labs, Gaithersburg, MD, U.S.A.) and $\left[{ }^{35} \mathrm{~S}\right]$ deoxyadenosine $5^{\prime}$ (alpha-thio) triphosphate (PerkinElmer Life Science Products, Boston, MA, U.S.A.) (24). The probe was labeled to a specific activity of $5-15 \times 10^{8} \mathrm{cpm} / \mu \mathrm{g}$. Before use, all labeled probes were centrifuged through Sephadex G-25 spin columns (Amersham Pharmacia Biotech) to separate unincorporated ${ }^{35} \mathrm{~S}$ dATP from labeled probe.

Image analysis and statistics. The density of mRNA and ligand binding in the fetal intestine was analyzed by using a MacIntosh-II-based image analysis system (IMAGE, Wayne Rasaband, Research Services Branch, National Institute of Mental Health, Bethesda, MD, U.S.A.). For each section, at 
least 10 microscopic fields were analyzed after background was subtracted. Densitometric data were expressed as a mean $\pm \mathrm{SD}$, and then converted to percentage of control, where control was $100 \%$. This was done to allow for comparison between experiments. Statistical analysis was performed using calculation of ANOVA.

\section{RESULTS}

There were a total of 39 female rats analyzed in this study. Thirteen were treated with saline, 13 with low-dose cocaine, and 13 with high-dose cocaine. One mother from the low-dose group escaped for $36 \mathrm{~h}$ and was euthanized. Nine out of 13 rats from the control group were pregnant $(69.2 \%), 10$ out of 12 from the low-dose group (83.3\%), and 6 out of 13 from the high-dose group (46.1\%). These differences were not statistically significant $(p=0.9775)$. The average number of pups that were delivered was similar among the groups -11.9 in the control group, 11.7 in the low-dose group, and 12.6 in the high-dose group $(p=0.6687)$. We killed the pregnant rats at various points during their gestation to ensure that there was a litter from each gestational age from E 16 until delivery. Thus,

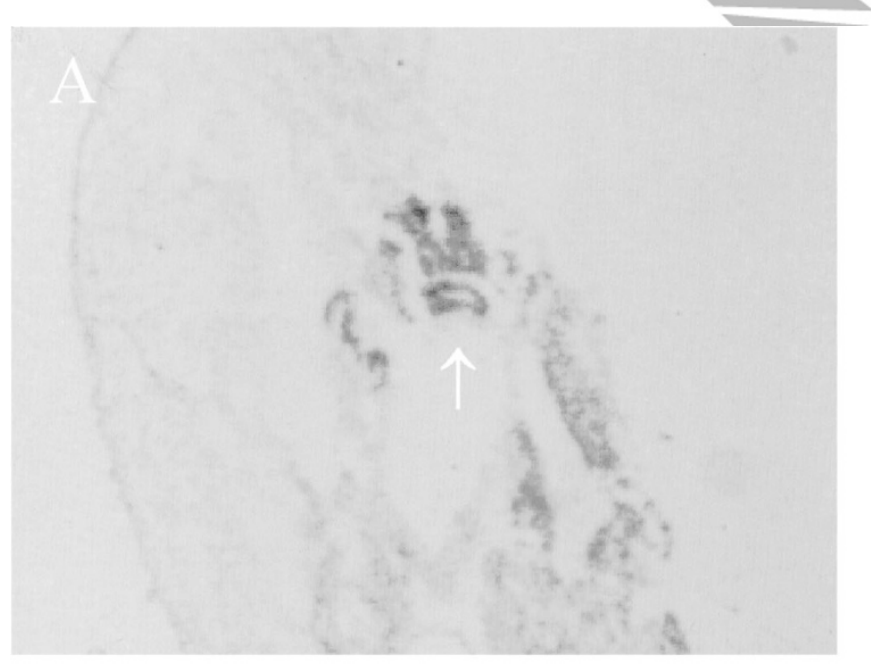

at $\mathrm{E} 16$, there were two litters in the control group, two in the low-dose group, and one in the high-dose group. At E 17, there was one litter each in the control, low-dose, and high-dose groups. At E 18, there were two litters in the control group, and one each in the low- and high-dose group. At E 19, there was one litter in the control group, two in the low-dose group, and one in the high-dose group. At E 20, there were two litters in the control and low-dose groups and one in the high-dose group. The remaining pregnant rats (one from each group) were allowed to deliver. Multiple pups from a single litter from each group were examined from E 16 to E 20.

We found that the $\alpha-2 \mathrm{~A}$ adrenergic receptor subtype was localized in the embryonic rat intestine by $\mathrm{E} 17$. When we quantified the gene expression of this receptor subtype, there was a significant down-regulation in the intestines of cocaineexposed pups (Fig. 1B, low dose; Fig. 1C, high dose) compared with controls (Fig. 1A). This down-regulation was apparent from $\mathrm{E} 17$, the first point in gestation at which this receptor could be localized, until near term-E 20. This did not appear to be a dose-dependent relationship. Figure 2 demonstrates the average densitometric data of multiple sections from animals

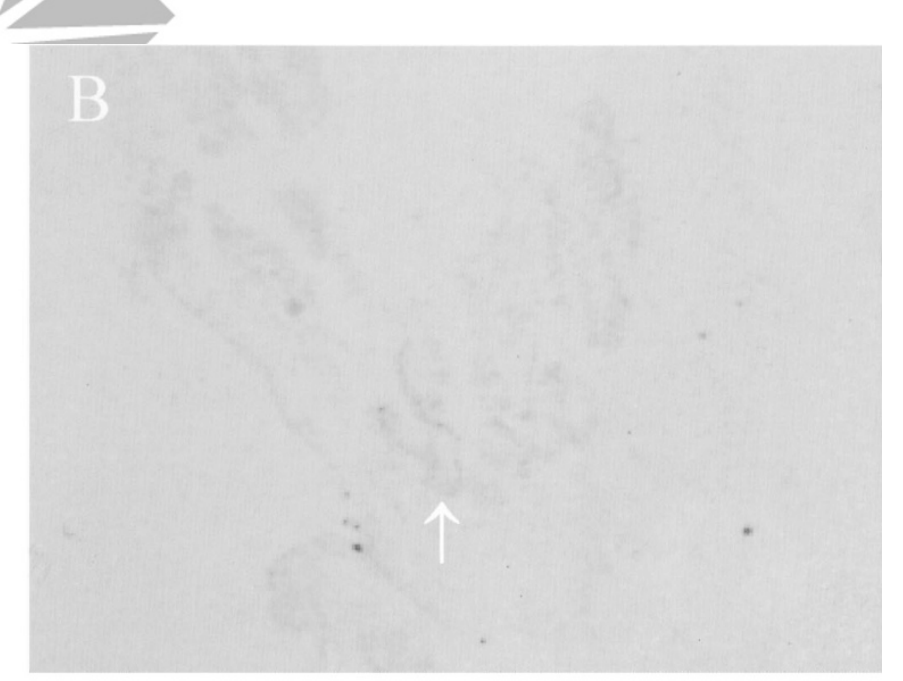

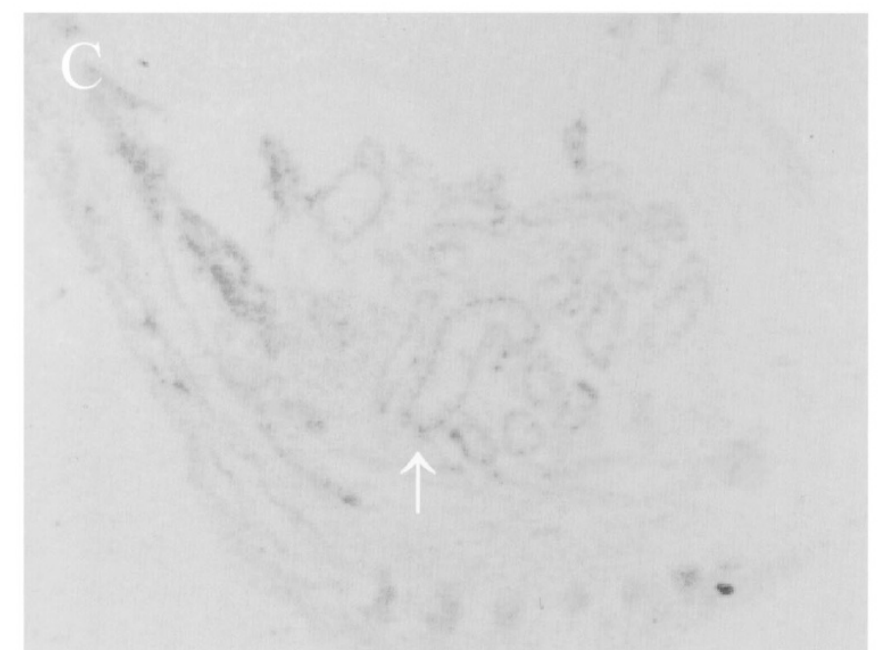

Figure 1. In-situ hybridization for the $\alpha$-2A adrenergic receptor subtype in the intestine of $\mathrm{E} 19$ rats exposed to saline $(A)$, low-dose cocaine $(B)$, and high-dose cocaine $(C)$ in utero. Arrows indicate intestinal signal. 


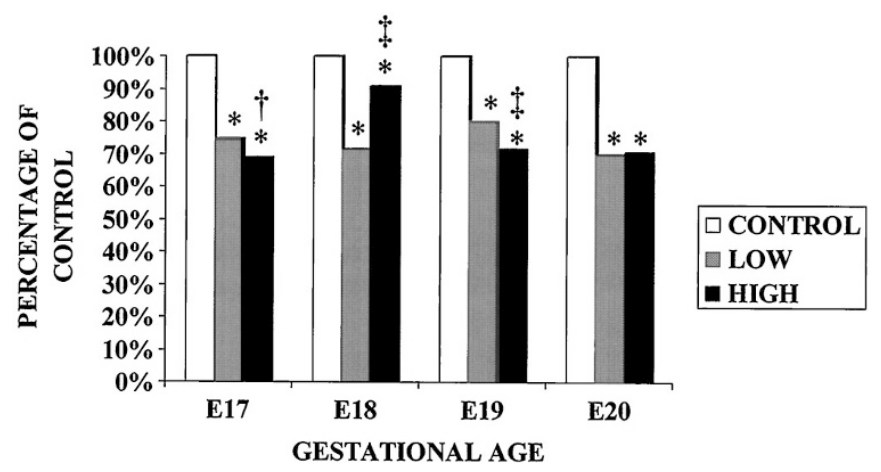

Figure 2. Comparison of the ontogenic expression of the $\alpha-2 \mathrm{~A}$ adrenergic receptor in the intestine of rat pups after maternal exposure to either saline or cocaine. Pregnant rats were injected with either saline (Control group), lowdose cocaine $(30 \mathrm{mg} / \mathrm{kg}$ ) (Low group), or high-dose cocaine $(75 \mathrm{mg} / \mathrm{kg})$ (High group) from E 5to E 20; values are expressed as percentage of control; ${ }^{*} p \leq$ 0.0001 vs Control group; $\uparrow p=0.02$ vs Low group; $₫ p \leq 0.0001$ vs Low group.

of different gestational ages from each treatment group. In E 17 animals ( $n=4$ for each group), the expression of the $\alpha-2 \mathrm{~A}$ receptor was $74.4 \%$ of control in the low-dose group ( $p<$ $0.0001)$ and $68.9 \%$ of control in the high-dose group $(p<$ $0.0001)$. There was also a statistical difference between the low and high groups $(p=0.02)$. In E 18 animals $(n=4$ for the control group, $n=5$ for the low- and high-dose groups), the expression of this receptor was $71.6 \%$ of control in the lowdose group $(p<0.0001)$ and $90.1 \%$ of control in the high-dose cocaine-treated animals $(p=0.0001)$; the difference between the low and high groups was also statistically significant $(p<$ $0.0001)$. In E 19 animals ( $n=5$ for all groups), the expression of the $\alpha-2 \mathrm{~A}$ receptor was $80 \%$ of control in the low-dose cocaine group $(p<0.0001)$, and $71.5 \%$ of control in the high-dose cocaine group $(p<0.0001)$. The difference between the low- and high-dose groups was also statistically significant $(p<0.0001)$. In E 20 animals $(n=5$ for all groups), the expression of the $\alpha-2 \mathrm{~A}$ receptor was $69.8 \%$ of control in the low-dose group $(p<0.0001)$ and $70.5 \%$ of control in the high-dose group $(p<0.0001)$. The difference between the low- and high-dose cocaine groups was not statistically significant $(p=0.7432)$.

\section{DISCUSSION}

Our results indicate that the $\alpha-2 \mathrm{~A}$ adrenergic receptor subtype is localized in the neonatal rat intestine, and that it is first evident at a gestational age of $17 \mathrm{~d}$. We also found that chronic in utero cocaine exposure substantially altered the gene expression of this receptor subtype in the intestines of fetal rat pups. Furthermore, these changes were perceptible at the earliest gestational age that receptor mRNA expression was identified. In this study, we observed a low rate of pregnancy. The lowest rate was in the high-dose cocaine group, though differences between the groups were not statistically significant. This may be due in part to the fact that we had requested delivery of the pregnant rats relatively early in gestation (E 3), so that we could establish prolonged prenatal cocaine exposure. The company, however, was unable to guarantee preg- nancy this early in gestation. However, statistical significance could possibly be seen with a larger sample size.

The influence of prenatal cocaine exposure on the expression of the $\alpha-2 \mathrm{~A}$ receptor in the intestine may represent the mechanism that may predispose these newborns to NEC. It has been demonstrated that when the adult intestine is exposed to hypoxia or ischemia, the circulation is capable of escaping to baseline conditions (26). The newborn intestine, however, is less efficient in this autoregulatory response, as there is insufficient dilation of resistance vessels and precapilllary sphincters (27). Thus, the immature intestine is more prone to injury. The $\alpha-2$ adrenergic receptor is thought to play a role in the autoregulatory process in the newborn intestine that responds to hypoxia and ischemia (22). There is evidence that there are actually two mechanisms involved in producing vasodilation in the newborn intestine. One is mediated by nitric oxide, and the other by the $\alpha-2$ adrenergic receptor (23). The nitric oxide pathway, which is thought to regulate basal vascular tone, may be disrupted in conditions of hypoxia or ischemia, thus rendering the $\alpha-2$ mediated yascular relaxation more significant (23). The downregulation of this receptor subtype that we demonstrated in this study may further exacerbate the already inefficient newborn autoregulatory response to intestinal ischemia. Thus, if fewer $\alpha-2$ receptors are available to produce vasodilation, these cocaine-exposed newborns may be subject to further intestinal injury.

We chose the low and high doses of cocaine $(30 \mathrm{mg} / \mathrm{kg}$ and $75 \mathrm{mg} / \mathrm{kg}$, respectively) based on the study by Buyukunal et al. (14), in which they describe histologic evidence of a dosedependent intestinal injury in fetal rats after in utero cocaine exposure. Interestingly, there did not appear to be a relationship between the in utero cocaine dose and the degree of down-regulation of the $\alpha-2 \mathrm{~A}$ receptor in the fetal intestine. One of the difficulties in clinical studies of antenatal cocaine exposure and its consequences for the neonate is controlling for the extent of abuse in the mother, which is widely variable. Our study indicates that higher dosage did not consistently result in the anticipated diminution of expression of this particular receptor in the intestine after cocaine exposure. At the various time points that we examined, high dosage produced either more significant, less significant, or similar changes in this receptor compared with low dosage. Thus, the infant born to a mother who occasionally uses cocaine may be at just as much risk for intestinal injury as the infant born to a mother with a history of heavy cocaine use.

In summary, we conclude that in utero cocaine exposure alters the gene expression of the $\alpha-2 \mathrm{~A}$ adrenergic receptor subtype in the neonatal rat intestine. This may represent one of the mechanisms responsible for the increased risk of NEC that may be seen in cocaine-exposed infants. Future studies are needed to examine the histology of the cocaine-exposed newborn intestine after an additional ischemic insult. In addition, these findings demonstrate changes only in the expression of this gene. Further investigation is warranted to examine whether or not this is reflected in functional activity of the gene, and whether other $\alpha-2$ adrenoceptor subtypes exhibit similar changes after cocaine exposure. 


\section{REFERENCES}

1. Frank DA, Zuckerman BS, Amaro H, Aboagye K, Bauchner H, Cabral H, Fried L, Hingson R, Kayne H, Levenson SM, Parker S, Reece H, Vinci R 1988 Cocaine use during pregnancy: prevalence and correlates. Pediatrics 82:888-895

2. Telsey AM, Merrit A, Dixon SD 1988 Cocaine exposure in a term neonate: necrotizing enterocolitis as a complication. Clin Pediatr 27:547-550

3. Hoyme HE, Lyons Jones K, Dixon SD, Jewett T, Janson JW, Robinson LK, Msall ME, Allanson JE 1990 Prenatal cocaine exposure and fetal vascular disruption. Pediatrics 85:743-747

4. Moore TF, Sorg J, Miller I, Keyt TC, Resnik R 1986 Hemodynamic effects of intravenous cocaine in the pregnant ewe and fetus. Am J Obstet Gynecol 155:883888

5. Miller MM, Rosario PG, Prakash K, Patel HK, Gerst PH 1990 Neonatal intestinal perforation: the "crack" connection. Am J Gastroenterol 85:767-769

6. Spinazzola R, Kenigsberg K, Usmani SS, Harper RG 1992 Neonatal gastrointestinal complications of maternal cocaine abuse. N Y State J Med 92:22-23

7. Hall TR, Zaninovic A, Lewin D, Barrett C, Boechat MI 1992 Neonatal intestinal ischemia with bowel perforation: an in utero complication of maternal cocaine abuse. AJR Am J Roentgenol 158:1303-1304

8. The TG, Young M, Rosser S 1995 In utero cocaine exposure and neonatal intestinal perforation: a case report. J Natl Med Assoc 87:889-891

9. Porat M, Brodsky N 1991 Cocaine: a risk factor for necrotizing enterocolitis. J Perinat $11: 30-32$

10. Downing GJ, Horner SR, Kilbride HW 1991 Characteristics of perinatal cocaineexposed infants with necrotizing enterocolitis. Am J Dis Child 145:26-30

11. Sehgal S, Ewing C, Waring P, Findlay R, Bean X, Taeusch HW 1993 Morbidity of low-birthweight infants with intrauterine cocaine exposure. J Nat Med Assoc 85:220224

12. Lopez SL, Taeusch HW, Findlay RD, Walther FJ 1995 Time of onset of necrotizing enterocolitis in newborn infants with known prenatal cocaine exposure. Clin Pediatr 34:424-29

13. Czyrko C, Del Pin CA, O’Neill JA, Peckham GJ, Ross AJ 1991 Maternal cocaine abuse and necrotizing enterocolitis: outcome and survival. J Pediatr Surg 27:414-421
14. Buyukunal C, Kilic N, Dervisoglu S, Altug T 1994 Maternal cocaine abuse resulting in necrotizing enterocolitis - an experimental study in a rat model. Acta Paediatr Suppl 396:91-93

15. Kilic N, Buyukunal C, Dervisoglu S, Erdil TY, Altiok E 2000 Maternal cocaine abuse resulting in necrotizing enterocolitis. An experimental study in a rat model II. Results of perfusion studies. Pediatr Surg Int 16:176-178

16. Gilman AG, Reill JW, Nies AS, Taylor P 1990 The Pharmacological Basis of Therapeutics, $8^{\text {th }}$ Ed. Pergamon Press, New York, p 319

17. Kable JW, Murrin LC, Bylund DB 2000 In vivo modification elucidates subtypespecific functions of $\alpha-2$ adrenergic receptors. J Pharmacol Exp Ther 293:1-7

18. Aantaa R, Marjamaki A, Scheinin M 1995 Molecular pharmacology of $\alpha$-2 adrenoceptor subtypes. Ann Med 27:439-449

19. Liu L, Loupar M 1997 Role of $\alpha$-2 adrenoceptors in the regulation of intestinal water transport. Br J Pharmacol Mar 120:892-898

20. Schiller LR, Santa Ana Ca, Morawski SG, Fordtran JS 1985 Studies of the antidiarrheal action of clonidine: effects on motility and intestinal absorption. Gastroenterology 89:982-988

21. Vieira-Coelho MA, Soares-da-Silva P 1998 Alpha 2-adrenoceptors mediate the effect of dopamine on adult rat jejunal electrolyte transport. Eur J Pharmacol 356:59-65

22. Vanhoutte PM, Miller VM 1989 Alpha-2 adrenoceptors and endothelium-derived relaxing factor. Am J Med 87(suppl 3C):1S-5S

23. Thorin E, Huang PL, Fishman MC, Bevan JA 1998 Nitric oxide inhibits alpha 2-adrenoceptor-mediated endothelium-dependent vasodilation. Circ Res 29:13231329

24. Young III WS, Mezey E, Siegel RE 1986 Vasopressin and oxytocin mRNAs in adrenalectomized and Brattleboro rats: analysis by in situ hybridization histochemistry. Brain Res Mol Brain Res 1:231-241

25. McCune SK, Voigt MM, Hill JM 1993 Expression of multiple alpha adrenergic receptor subtype messenger RNAs in the adult rat brain. Neuroscience 57:143-151

26. Shepherd AP, Mailman D, Burks TF, Granger HJ 1973 Effects of norepinephrine and

sympathetic stimulation on extraction of oxygen and ${ }^{86} \mathrm{Rb}$ in perfused canine small bowel. Circ Res 33:166-174

27. Nowicki PT, Nankervis CA 1994 The role of the circulation in the pathogenesis of necrotizing enterocolitis. Clin Perinatol 21:219-234 